\title{
Zaratustra retórico e sofista,
}

\author{
Benedetta Zavatta***
}

\begin{abstract}
Resumo: $\mathrm{O}$ artigo pretende explorar o lugar que a retórica ocupa no pensamento de Nietzsche. Partindo do posicionamento que o filósofo tem em sua época, e pela luta que trava contra o desprezo que os alemães e os modernos têm da arte retórica, pretende-se mostrar as formas pelas quais Nietzsche revaloriza a retórica. Retomando o caráter positivo que Aristóteles atribuia à retórica como uma dynamis, Nietzsche a considera como uma disposição biológica e natural, e que a própria linguagem é resultado de artes retóricas. Apelando, ainda, à tradição dos antigos sofistas, com quem compartilha a visão sobre a íntima relação entre linguagem e retórica, e por isso mesmo desconfia da capacidade de atingir a verdade, o filósofo alemão cria a figura de Zaratustra para responder ao apelo de uma época de superação dos valores religiosos e metafísicos graças ao declínio da vontade de verdade. Assim falou Zaratustra deve, portanto, ser compreendido junto ao contexto de um ceticismo renovado, no qual a verdade não é algo já dado, mas aquilo que toda vez o discurso cria e impõe como tal, em um suceder-se infinito de perspectivas.
\end{abstract}

Palavras-chave: Zaratustra, retórica, linguagem, sofista.

\footnotetext{
*Tradução de Anna Maria Lorenzoni. **Revisão técnica de Stefano Busellato.

**Membro do Instituto de Textos e Manuscritos Modernos da École Normale Supérieure de Paris, Paris, França.

Correio eletrônico: benedettazavatta@libero.it.
} 
Zavatta, B.

\section{Uma arte desprezada e mal compreendida}

$\mathrm{Na}$ época de Nietzsche, recaía sobre a retórica, desde longa data, um preconceito de matriz iluminista, o qual a considerava um embelezamento estilístico desnecessário - e, em última instância, um obstáculo à clareza da comunicação - ou uma estratégia enganadora destinada a ocultar uma falta de conteúdo real. Como destaca Goth, até Nietzsche, a retórica, na Alemanha, havia sido quase sempre compreendida numa acepção pejorativa, frequentemente acompanhada do adjetivo "mera $[b l o \beta]$ "1, sem, contudo, ser feita uma distinção entre a sua versão "corrompida" e aquela "autêntica"2. A depreciação da retórica era, por um lado, relacionada ao raciocínio científico, o qual a acusava de redundância, e, por outro lado, provinha da comparação com a poesia, com respeito a qual era considerada superficial e insincera ${ }^{3}$.

Nietzsche, que, durante seus anos de ensino na Universidade de Basileia, concentra grande parte de sua atenção a essa disciplina, tratando-a tanto de um ponto de vista histórico como de um ponto de vista propriamente teórico, é bem consciente da longa tradição de desprezo que recaía sobre ela e opõe-se explicitamente a tal tradição. Na abertura de Exposição da retórica antiga [Darstellung der antiken Rhetorik], curso realizado no semestre invernal de 1872/73, Nietzsche cita uma passagem do Ensaio sobre o entendimento humano de Locke, no qual este sustenta que a retórica representa um uso particular de discurso - artificioso e "desviante" no que se refere à sua modalidade natural e padrão - por meio do qual o orador visa suscitar, no ânimo do ouvinte, um envolvimento emotivo, lhe perturbando o entendimento até o ponto de convencê-lo a lhe abraçar as próprias teses também quando elas não são objetivamente as

1 J. Goth, 1970, p. 9.

2 J. Goth, 1970 p. 11.

3 J. Goth, 1970, p. 28.

98 | Cad. Nietzsche, Guarulhos/Porto Seguro, v.39, n.2, p. 97-122, maio/agosto, 2018. 
melhores (KGW II, IV, p. 415). Essa consideração negativa da retórica como arte insidiosa e enganadora, inimiga do raciocínio, é encontrada também em Kant. Na Crítica do juízo, tratando das artes verbais, este claramente subordina a oratória à poesia: enquanto esta última é digna de respeito e admiração por ser expressão sincera da interioridade do poeta e obra do gênio, a retórica, ligada à esfera da exterioridade e da aparência, ao contrário, é desprezível, uma vez que visa enganar e confundir a realidade das coisas ${ }^{4}$. Ernst Robert Curtius, em Literatura europeia e idade média latina (1943), registra e deplora o tão enraizado sentimento de desconfiança dos alemães com relação a essa arte, observando: “A retórica não encontra lugar em nosso mundo cultural. $\mathrm{O}$ alemão parece ter uma desconfiança inata com relação a ela [...] Também a retórica antiga frequentemente era considerada por parte dos intelectuais alemães, até os tempos mais recentes, como uma aberração"s.

Entre as razões desse menosprezo, Curtius atribui particular importância ao fato de que, enquanto os povos latinos "têm familiaridade com a retórica por uma predisposição e pela herança de Roma"6, na Alemanha, uma semelhante tradição de retórica política, entendida como arte republicana ligada ao exercício da democracia, é completamente ausente. A única tradição de retórica que os alemães conhecem é aquela religiosa: não por acaso, como observa Nietzsche, a Bíblia de Lutero é a primeira e insuperada obra-prima da literatura alemã (Cf. KGW VI, II, p. 198).

Nesse desprezo generalizado com relação à retórica, talvez seja exceção apenas Jacob Burckhardt que, na Era de Constantino, $o$ Grande, a exprime como uma expressão natural da harmonia e do valor artístico da vida grega. "Para os antigos, a retórica, com suas artes acessórias, se apresenta como o mais indispensável integramento

4 I. Kant, 1999, § 51, 1999, p. 157. Cf. KGW II, IV, p. 416.

5 E.R. Curtius, 1992, p. 73-74.

6 E.R. Curtius, 1992, p. 74. 
Zavatta, B.

da bela e livre, embora harmonicamente regulada, existência das suas artes, da sua poesia"7. Burckhardt destaca como, na antiguidade, a retórica representava uma forma de educação do homem na sua totalidade, física e espiritual, e era, portanto, considerada um componente essencial da virtude. Apenas na grosseira barbárie da vida moderna, com o seu ritmo febril e a sua total ausência de sensibilidade para o belo, a retórica pode aparecer como algo artificioso e supérfluo. Nessa escola se educa Nietzsche que, durante os anos de docência em Basileia, segue as preleções de Burckhardt sobre a cultura grega. $\mathrm{Na}$ aula inaugural do ciclo Exposição da retórica antiga, dedicada ao "conceito de retórica", Nietzsche contrapõe a imagem que os antigos tinham da retórica confrontando-a com aquela dos modernos, observando:

O extraordinário desenvolvimento da mesma faz parte dos tratos específicos que diferenciam os antigos dos modernos: em tempos recentes, essa arte sofre de uma grave ausência de consideração e, quando é utilizada, mesmo em seu melhor esforço da parte de nós modernos, aparece como diletantismo e grosseira empiria (KGW II, IV, p. 415).

Analogamente a Burckhardt, Nietzsche conclui, portanto, que, enquanto na antiguidade a retórica representava o vértice da educação e "a suprema atividade espiritual do homem politicamente educado" (KGW II, IV, p. 416), na modernidade, lamentavelmente, ela é completamente mal compreendida e escassamente levada em consideração.

\section{As preleções de Basileia: a linguagem é, por sua natureza, retórica}

A revalorização nietzschiana da retórica possui motivações muito profundas. $\mathrm{Na}$ introdução ao curso sobre gramática latina,

7 J. Burckhardt, 1990, p. 296.

$100 \mid$ Cad. Nietzsche, Guarulhos/Porto Seguro, v.39, n.2, p. 97-122, maio/agosto, 2018. 
de 1869, intitulada Sobre a origem da linguagem (Vom Ursprung der Sprache), Nietzsche estabeleceu que "A linguagem não é um trabalho consciente de indivíduos, nem de uma maioria" (KGW II, II, p. 186) ${ }^{\mathbf{z}}$, mas o produto de um instinto inconsciente que reside na profundeza da alma humana. Assim, na Exposição da retórica antiga, ele identifica esse instinto com uma força de persuasão que responde à necessidade biológica do ser humano de "acreditar", ou seja, de estabelecer um mundo estável no qual se mover. A linguagem surgiria, portanto, com o objetivo de impor a própria visão subjetiva das coisas como universalmente válida, de modo a criar uma realidade sobre a qual seja possível confiar estavelmente e fazer referência univocamente. Segundo Nietzsche, a linguagem é, portanto, em sua mais autêntica e originária natureza, retórica 9

No que diz respeito à definição de retórica, Nietzsche remonta àquela de Aristóteles, considerada "autenticamente filosófica e maximamente influente sobre as posteriores" (KGW II, IV, p. 419). Aristóteles é, de fato, o primeiro a atribuir à retórica uma especificidade particular e um domínio de exercício bem definido, salvaguardandolhe a dignidade e a autonomia. Na obra homônima, Aristóteles define a retórica "não como uma episteme, tampouco uma techne, mas uma dynamis que pode, porém, ser conduzida ao nível de techne" (KGW II, IV, p. 419). Nietzsche segue observando: "Chamamos um autor, um livro ou um estilo 'retórico' quando observamos neles um uso consciente de meios artísticos [Kunstmittel] de discurso, sempre com uma leve reprovação" (KGW II, IV, p. 425), sem nos darmos conta de que, na realidade, esses artifícios conscientemente empregados não passam de uma continuação e uma intensificação daqueles inconscientemente já em ação na linguagem. Segundo Nietzsche, de fato, aquilo que se chama "retórico" para designar os meios de uma arte consciente [als Mittel bewußter Kunst], foi

8 KGW II, II, p. 186.

9 Cf. B. Vickers, 1994, p. 230. 
Zavatta, B.

ativo, na linguagem e em seu desenvolvimento, como meio artístico inconsciente [als Mittel unbewußter Kunst]. Sendo assim, a conclusão à qual Nietzsche chega é que, aquilo que comumente se entende como retórica, nada mais é que um "aperfeiçoamento [Fortbildung] dos meios artísticos [Kunstmittel] intrínsecos à linguagem conduzido à clara luz do intelecto". Portanto, "não existe uma "naturalidade" não retórica da linguagem à qual se poderia apelar: a linguagem é resultado de artes puramente retóricas" (KGW II, IV, p. 425).

Desses apontamentos, emerge como a retórica é, para Nietzsche, não somente um modo particular de usar a linguagem - como para Aristóteles -, mas também e acima de tudo a força que rege seu próprio surgimento. $\mathrm{O}$ propósito que se busca por meio da linguagem, não é efetivamente aquele de "dizer a verdade", mas aquele de impor a própria percepção subjetiva de um fenômeno como "verdadeira", isto é, como universalmente válida. A força de "encontrar e de colocar em cada coisa aquilo que suscita um efeito e uma impressão", chamada por Aristóteles de "retórica", é, portanto, para Nietzsche, simultaneamente "a essência da linguagem [das Wesen der Sprache]" (KGW II, IV, p. 425). A linguagem não tem condições de reportar exaustivamente à realidade das coisas, mas simplesmente de exprimir uma perspectiva, que permanece sempre subjetiva e parcial. "A linguagem é retórica, pois pretende transmitir [übertragen] unicamente uma doxa, não uma episteme" (KGW II, IV, p. 426).

A retórica se torna, assim, para Nietzsche, a chave para empreender uma "crítica do conhecimento baseada e orientada sobre a crítica da linguagem"10. Na retórica, compreendida como estruturação artística consciente do discurso, vêm à luz aqueles procedimentos que são a origem da linguagem enquanto tal, quais sejam, a sinédoque, a metonímia e a metáfora ${ }^{11}$. Na retórica, como arte do discurso, transparecem os meios através dos quais se constrói

10 J. Kopperschmidt, 1994, p. 47.

11 Veja-se B. Zavatta, 2013.

102 | Cad. Nietzsche, Guarulhos/Porto Seguro, v.39, n.2, p. 97-122, maio/agosto, 2018. 
a nossa visão de mundo, e manifesta-se também a ideologia oculta que caracteriza inevitavelmente cada ato nosso de comunicação. A força de persuasão que se exercita explicitamente no discurso de um orador aparece efetivamente como a intensificação consciente da força à origem da linguagem mesma, que não é vontade de verdade, mas vontade de potência. A linguagem não visa, a saber, comunicar simplesmente uma opinião sobre o mundo, mas impor essa opinião aos outros como verdadeira. Escreve Nietzsche: "[A linguagem], assim como a retórica, não faz referência ao verdadeiro, à essência das coisas, não pretende instruir, mas transmitir aos outros um estímulo e uma opinião subjetiva [eine subjektive Erregung und Annahme]" (KGW II, IV, p. 425-426). A retórica explícita torna evidente a intenção oculta continuamente operante na linguagem, que não é uma intenção teórica, mas pragmática, ou seja, o desejo de afirmação e de reconhecimento do próprio ponto de vista. Como adequadamente observa Kopperschmidt, já nesses apontamentos juvenis se registra, no pensamento de Nietzsche, "uma dispensa da pretensão de verdade [Wahrheitsanspruch] em prol da vontade de exercitar um efeito [Wirkungswillen], uma dispensa da pretensão epistêmica ao conhecimento [Erkenntnisanspruch] em prol da vontade pragmática de autoafirmação [Selbstbehauptungswille]" 12.

Em última instância, aquilo que emerge das preleções da Basileia é que a retórica não representa, para Nietzsche, um uso particular da linguagem, afastando-se de um suposto nível ordinário ou standard, mas o único modo de construção de discurso: também a assim chamada comunicação científica, cuja neutralidade e objetividade a retórica é acusada de perturbar, ou a comunicação da poesia, que parece emanar diretamente da alma do poeta em toda sua espontaneidade e autenticidade, são, na realidade - mais ou menos conscientemente - nada além de construções retóricas. "Aquilo que comumente se chama discurso", conclui Nietzsche, "na

12 J. Kopperschmidt, 1994, p. 53. 
Zavatta, B.

verdade, é totalmente uma figuração" [eingentlich ist alles Figuration, was man gewöhnliche Rede nennt]" (KGW II, IV, p. 427).

\section{Impossibilidade da verdade e necessidade da retórica}

Hans Blumenberg oportunamente distingue, no interior da tradição filosófica, duas maneiras fundamentais de entender a retórica: "A retórica tem a ver com as consequências do processo de uma verdade ou com o embaraço subsequente à impossibilidade de alcançar uma tal verdade"13. Fundador da primeira concepção é Platão, que admite e legitima a retórica exclusivamente como comunicação de uma verdade filosófica àqueles que não são capazes de alcançá-la sozinhos. O próprio Nietzsche assinala, nas Exposições da retórica antiga, a passagem do Fedro na qual Sócrates explica que a posse da verdade é acompanhada da necessidade e do desejo de comunicá-la, ou aquela do Político, na qual se exprime a convicção de que a multidão deve ser persuadida com meios retóricos ${ }^{14}$. Sendo assim, Nietzsche conclui que Platão condena a retórica quando esta não serve aos objetivos da filosofia, ao passo que a legitima e, de fato, exorta a recorrer a ela, na medida em que ela ajuda a conduzir a alma junto à verdade e ao bem (KGW II, IV, p. 419). Em contrapartida, o recurso à retórica, feito pelos sofistas - e, sob o exemplo deles, também de Nietzsche -, resulta da tese da impossibilidade de alcançar a verdade. Nietzsche opõe-se à concepção platônica de retórica, tendo como base a convicção de que o homem não possui acesso à verdade e que a linguagem não é capaz de exprimir adequadamente a essência das coisas, mas que se limita a comunicar impressões inteiramente subjetivas. "O homem criador de linguagem [der sprachbildende

13 H. Blumenberg, 1987, p. 86.

14 Cf. KGW II, IV, p. 418; Platão, Fedro, 273 e; Politico, 304 d. Além desses dois diálogos, Nietzsche recorda a República (376 e), na qual Platão distingue dois tipos de discurso: verdadeiros e falsos. A retórica, como o mito, pertence ao segundo tipo. O recurso a falsidades, da parte dos governantes, é, porém, justificado se eles visam o bem dos próprios cidadãos (Cf. KGW II, IV, p. 419).

104 | Cad. Nietzsche, Guarulhos/Porto Seguro, v.39, n.2, p. 97-122, maio/agosto, 2018. 
Mensch] não capta coisas ou processos [Dinge oder Vorgänge], mas impulsos [Reize]" (KGW II, IV, p. 426): [A partir] destes, cria uma imagem do mundo que se expressa através dos sons, a qual, entretanto, está em uma relação não necessária, mas puramente estética, com aquilo que a estimulou. Trata-se, portanto, de uma elaboração livre que, atravessando esferas diversas, não dá qualquer garantia de correspondência. Sendo assim, "não são as coisas que penetram a consciência, mas o modo como nos relacionamos com elas, o pithanon" (KGW II, IV, p. 426). A verdade não pode ser apanhada pelo sujeito, tampouco ser reproduzida de maneira confiável. O sujeito só pode captar as características salientes [Markmale] das coisas, que resultam da relação extremamente pessoal que mantém com elas.

Blumenberg reconduz esses dois modos de entender a retórica - como comunicação de uma verdade que está em processo ou como instrumento de compensação pela sua perda - a dois diferentes modelos antropológicos, quais sejam, respectivamente, a ideia de homem como ser "rico", que "excede", "transcende" a determinação biológica dos animais, e a ideia de homem como ser "pobre", carente de dispositivos instintuais adequados para a sobrevivência e, portanto, constrangido a inventar meios artificiais que permitam sua adaptação ao ambiente. A carência de estruturas predeterminadas de adaptação e de códigos a serem inseridos oportunamente no interior daquele cosmo perfeitamente regrado - que é o mundo natural - constrangeria o homem a desenvolver instrumentos, como a linguagem, para se comunicar com os seus semelhantes e, assim, dividir necessidades e intenções. De acordo com esse segundo modelo antropológico, o homem recorre à retórica para superar a ausência de verdade à qual lhe confiam os seus aparatos cognoscitivos. Escreve Blumenberg: “Agir é a compensação da ‘indeterminação’ do ser humano, e a retórica é a extenuante produção daquelas concordâncias que devem assumir a posição do fundo 'substancial' dos códigos, de modo que o agir se 
Zavatta, B.

torne possível"15. Nesse segundo caso, portanto, a linguagem não é meio de comunicação de uma verdade que se possui ou expressão de uma realidade objetivamente dada, mas o instrumento através do qual se cria o consenso sobre aquilo que é verdadeiro e aquilo que é real ${ }^{16}$.

É esse segundo modelo antropológico - delineado por Herder e, posteriormente transformado, com Gehlen, em protagonista da antropologia do século XX - que Nietzsche adota, como aparece de maneira evidente em Sobre verdade e mentira em sentido extramoral. No início desse breve fragmento, os seres humanos são definidos os "mais infelizes, mais delicados e mais transitórios [unglücklichsten delikatesten vergänglichsten]" (KGW III, II, p. 369) organismos na natureza, que superam a própria inadequação biológica criando, por meio da cultura, um ambiente artificial no qual podem sobreviver. Ao homem não é permitido se relacionar com a realidade sem mediações: a sua relação com ela deve ser necessariamente mediada, indireta, ou seja, "metafórica". Sendo assim, o ser humano não tem nenhum interesse pela verdade enquanto tal, mas apenas pelo seu valor com vistas à sobrevivência. A criação de um mundo sobre o qual se possa confiar é, em última instância, segundo Nietzsche, o único objetivo do criador de linguagem.

Por outro lado, há que se considerar que a "descoberta", da parte de Nietzsche, da retórica - que ocorreu por volta do fim de 1872 - é concomitante ao abandono do paradigma metafísico schopenhaueriano, segundo o qual a música era expressão direta e adequada da essência do mundo. A retórica como transmissão de uma doxa passa, portanto, a ser importante para Nietzsche no

15 H. Blumenberg, 1987, p. 89.

16 Para os gregos, recorda Blumenberg, era um bom hábito empregar a retórica para atingir o consenso com os próprios pares, enquanto que, na relação com os bárbaros, se poderia recorrer ao uso da força. Apenas a partir do momento em que a filosofia reivindicou possuir verdades eternas e certezas definitivas sobre as quais não se era admitido discutir, a retórica passou a ser olhada com desprezo e considerada um perigo (H. Blumenberg, 1987p. 92).

$106 \mid$ Cad. Nietzsche, Guarulhos/Porto Seguro, v.39, n.2, p. 97-122, maio/agosto, 2018. 
momento no qual se manifesta a impossibilidade humana de alcançar uma episteme, um conhecimento verdadeiro acerca das coisas. Certamente tiveram influência sobre essa evolução do pensamento de Nietzsche os resultados das pesquisas de linguística históricocomparativa, então em forte expansão, que o levaram a acolher o dado da não transcendenciabilidade da linguagem e a considerar a multiplicidade de línguas como prova subsequente da impossibilidade de se referir à realidade de maneira unívoca e objetiva. A existência de múltiplos códigos linguísticos, cada qual caracterizado por uma extensão semântica nunca perfeitamente congruente com aquela dos demais, bem como a evolução histórica de cada língua, que testemunha a transformação incessante do significado das palavras, são dados que corroborarão a tese de que a linguagem não oferece uma descrição adequada da realidade, mas exprime simplesmente uma percepção dela, histórica e culturalmente condicionada, portanto, inevitavelmente arbitrária e parcial. Cada comunidade linguística possui as próprias convenções para designar e descrever as coisas, para decidir qual coisa, em um dado momento, deve se aplicar, no seu interior, como "verdadeiro" e "real".

Essas convenções, por sua vez, não são arbitrariamente escolhidas, mas refletem as "condições de existência [Existenzbedingungen]" de uma determinada raça ${ }^{17}$. Reexaminando o transcendental kantiano de um ponto de vista fisiológico, Nietzsche conclui que a base sobre a qual é possível construir um consensus é primariamente biológica e consiste na uniformidade substancial dos

17 Kopperschmidt observa que, uma vez que, na maneira com a qual conceitualizamos o mundo, apenas as nossas condições de existência têm valor - as quais implicam necessariamente uma perspectiva antropomórfica e antropocêntrica -, a questão sobre se a percepção é verdadeira ou falsa priva-se de significado: ela é a única possível para nós. (cf. J. Kopperschmidt, 1994, p. 51). O perspectivismo não é, portanto, um jogo estetizante, como queria Derrida, ou uma substituição de paradigmas em função da moda, como sustenta Rorty, pois o indivíduo não escolhe a própria visão de mundo: ela surge com a mais rigorosa necessidade, em parte, da organização psicofísica que compartilha com o restante da humanidade, e, em parte, dos condicionamentos históricos e culturais particulares aos quais foi sujeitada a estirpe linguística à qual pertence. 
Zavatta, B.

órgãos sensoriais, graças aos quais a diversidade individual no modo de perceber e experenciar a realidade permanece circunscrita dentro de certos limites. Vemos em uma anotação de 1872/73: "O incrível consenso dos homens com respeito às coisas demonstra a perfeita homogeneidade de seu aparato perceptivo [die volle Gleichartigkeit ihres Perceptionsapparates]" (KGW III, IV, p. 56; OFN III, III, II, p. 53). É, portanto, a variedade das condições de existência das diversas raças que determina as diferenças de semantização entre línguas diversas, dado que a seleção das características salientes, com base às quais um objeto é nominado e conceitualizado, é determinada pelo interesse com o qual eventualmente dirige-se a ele. É a necessidade específica de uma determinada raça em um momento histórico preciso que decide aquilo que é relevante em um objeto. Aquilo que acreditamos conhecer sobre as coisas é, portanto, em última instância, apenas uma projeção metafórica das nossas condições de existência. Escreve Kopperschmidt:

Porque apenas esse interesse, e não quiçá o "conhecimento das coisas [Wissen über die Dinge]", decide quais "características distintivas" selecionamos nelas como importantes para nós (sinédoque), quais propriedades agrupamos tendo como base nosso "juízo" (metonímia), mediante quais "transposições de significado" tornamos as coisas familiares a nós (metáfora)" ${ }^{18}$.

\section{Os primeiros "espíritos livres": os sofistas}

Historicamente, quem primeiro chegou ao entendimento de que a linguagem não comunica a verdade, mas a cria, foram os sofistas. Reconhecendo o poder performativo do discurso, os sofistas recusaram se submeter à tirania de uma verdade "única", atraindo, deste modo, a reprovação e a condenação dos filósofos, para os quais "sofisma" se torna sinônimo de raciocínio privado de solidez e seriedade. A imagem deles tradicionalmente transmitida é aquela de

18 J. Kopperschmidt, 1994, p. 54.

108 | Cad. Nietzsche, Guarulhos/Porto Seguro, v.39, n.2, p. 97-122, maio/agosto, 2018. 
uma companhia de hábeis "mercantes do saber", que fazem comércio de sua própria cultura e de suas próprias competências. Hegel os apresenta como educadores de profissão que, em vez de se dedicarem à contemplação do mundo físico ou metafísico, peregrinam de cidade em cidade exercitando a docência "como negócio ou indústria, [...] substituindo as escolas" "19. Barbara Cassin, referindo-se ao legado de Mario Untersteiner, reabilita vigorosamente os sofistas do desprezo da tradição filosófica, reconhecendo, na base de suas reflexões sobre o caráter ambivalente do logos - sobre a sabedoria trágica que brota dessa ambivalência - uma matriz anti-idealista, e não cético-niilista. Se a ontologia que nasce com Parmênides e Platão considera o "dizer" como um efeito do ser e a linguagem como instrumento de comunicação da verdade, Cassin identifica, na sofística, o nascimento de um movimento contrário, que ela denomina "logologia", para o qual, em vez disso, o ser é um efeito do "dizer". Segundo os sofistas, o ser não é aquilo que a palavra revela, mas aquilo que o discurso $\operatorname{determina}^{20}$.

A filosofia de Nietzsche pode ser lida precisamente em substancial continuidade com essa tradição. Nietzsche sempre celebrou a sofística como o momento mais alto de lucidez e coragem na história da filosofia, concentrando sobre ela uma atenção particular nos anos de 1887/88, quando ele retoma com maior força a crítica à ideia de verdade em cada acepção possível. Nesses fragmentos tardios, Nietzsche observa com pesar que a cultura grega não chegou de fato a produzir os seus tipos mais altos, mas trilhou com Sócrates a via de uma irrefreável decadência. Diferentemente dos filósofos que o seguiram - quais sejam: Platão e Aristóteles - [segundo Nietzsche], o sofista permanece uma autêntica expressão da cultura helênica, mesmo que se trate de uma cultura em "transição", que é forçada a se confrontar com algo diferente de si mesma e é forçada a colocar

19 G.W.F. Hegel, 1930, p. 7.

20 Cf. B. Cassin, 2002, p. 57. 
Zavatta, B.

em discussão a singularidade de seus próprios valores (KGW VIII, II, p. 409). Nesse momento tão delicado de transição, os sofistas "afloram a primeira crítica da moral, o primeiro conhecimento em profundidade da moral", uma vez que tomam consciência de que os juízos de valor são localmente condicionados e compreendem que nenhuma moral é, em termos absolutos, melhor do que as outras, mas que sempre precisa ser discursivamente fundada e justificada dialeticamente. A conclusão escandalosa à qual os sofistas chegam é, portanto, a de que "não existe 'uma moral em si', um 'bem em si', que é uma fraude falar de "verdade' nesse campo" (KGW VIII, III, p. 84). Nietzsche denuncia o fato de que, embora tenha sido a expressão mais autêntica da essência grega nesse período de transição, a sofística foi considerada responsável pela mesma dissolução moral e política à qual se assistia. Reduzindo os valores aos efeitos do discurso, os sofistas anularam a linha de demarcação entre um bem e um mal absolutos. "O bem e o mal de origens diversas se confundem: o limite entre o bem e o mal se anula... Eis o 'sofista' - o filósofo, pelo contrário, é a reação", escreve Nietzsche em um fragmento de 1887/88 (KGW VIII, II, p. 409). Já em sua Introdução aos diálogos platônicos Nietzsche distinguia entre os seguidores de Heráclito, aqueles que "não confiavam mais nos sentidos e perdiam a base para todo saber", como Crátilo - o qual chega à "consequência extrema" de "não poder dizer mais nada", limitando-se a "indicar com o dedo" [mit dem Finger zu deuten]" -, e aqueles que, como Protágoras, "se deixavam impressionar menos e concediam apenas que, da aisthesis, não resulta um conhecimento universalmente válido [eine allgemein gültige Erkenntniß]", mas unicamente um conhecimento individual. É do "desespero sombrio" de Crátilo que Nietzsche vê surgir a solução de Platão, o qual, temendo que fosse anulado "todo viver moral" e o indivíduo fosse abandonado "sem qualquer apoio [Halt], [...] medida [Maß] ou limite [Grenze]", postulou, por "reação", um mundo suprassensível de essências eternas ao qual se referir (KGW 
II, IV, p. 151). A solução de Protágoras é, em vez disso, aquela da sofística, que não perde a esperança na verdade, mas simplesmente a redimensiona, concebendo-a como a forma individual que o homem confere ao mundo por meio da linguagem. Apropriando-se da riqueza de pensamento e da força polêmica dessa tradição, Nietzsche volta a salientar como o discurso não é mera comunicação daquilo que é, mas processo de construção ativa do real.

\section{Zaratustra como médico da cultura e sofista}

Mediante a corajosa operação de destruição da verdade e relativização da moral, Nietzsche reconhece os sofistas como seus predecessores e os define, em virtude de sua grande "probidade intelectual [intellektuelle Rechtschaffenheit]" (KGW VIII, III, p. 84), espíritos livres par excellence. $\mathrm{O}$ contexto no qual antigamente surgiu a sofística é visto agora reproduzido em época moderna, uma vez que a busca pela verdade, que animava a filosofia platônico-cristão, finalmente se realizou com a descoberta da mesma impossibilidade e consequente auto supressão da moral"1. "Tendo a veracidade cristã tirado uma conclusão após a outra, tira finalmente a sua mais drástica conclusão, a sua conclusão contra si mesma; mas isso ocorre quando coloca a questão: "o que significa toda vontade de verdade?"” (KGW VI, II, p. 426).

Nietzsche cria a figura de Zaratustra precisamente como uma encarnação deste destino: "A moral que supera a si mesma pela veracidade [die Selbstüberwindung der Moral aus Wahrhaftigkeit], os moralistas que superam a si próprios tornam-se seu próprio oposto - eu mesmo - isso significa o nome de Zaratustra sob minha boca" (KGW VI, III, p. 365). O persa Zaratustra, que foi o primeiro a "traduzir a moral em termos metafísicos" (KGW VI, III, p. 365),

21 Observa Nietzsche: “Todo processo do conhecimento gnosiológico e moral nos fez voltar aos sofistas..." (KGW VIII, III, p. 84). 
Zavatta, B.

será, segundo Nietzsche, também o primeiro a reconhecer esse erro terrível e assinalar uma inversão de tendência.

Assim falou Zaratustra deve, portanto, ser compreendido junto ao contexto de um ceticismo renovado, no qual a verdade não é algo já dado, mas aquilo que toda vez o discurso cria e impõe como tal, em um suceder-se infinito de perspectivas. Vejamos, em um fragmento do outono de 1887:

A vontade de verdade é um fazer firme [fest-machen], um fazer verdadeiroduradouro [wahr-dauerhaft-machen] [...] A verdade não é, portanto, algo que exista e possa ser encontrado, ser descoberto - mas algo a ser criado [zu schaffen ist] e que dá nome a um processo, antes a uma vontade de subjugação que em si não tem fim: introduz a verdade, como um processum in infinitum, um determinar ativo, não um tomar consciência de algo <que> seja "em si" fixo e determinado. É uma palavra para a "vontade de potência" (KGW VIII, II, p. 47).

A este respeito, Volker Gerhardt fala de uma "revolução estética" na filosofia de Nietzsche, pela qual, "no lugar do conhecimento, da consciência [Bewusstsein], da filosofia e da verdade em suas acepções metafísicas", tomaria lugar a arte: "A arte torna possível não o sentido da realidade, mas a vida"22. Segundo Gerhardt, a arte, em Nietzsche, finalmente tomaria controle sobre o conhecimento, a retórica sobre a filosofia. Tem razão, entretanto, Anne Tebartz-van Elst ao destacar como Nietzsche, uma vez superada a metafísica do artista em $O$ nascimento da tragédia, não visa mais uma inversão do platonismo, mas a superação da própria dicotomia entre mundo verdadeiro e mundo aparente, bem como - consequentemente -, daquela entre arte e verdade. Particularmente, nos fragmentos e nas obras posteriores a 1881, a arte se torna o modo pelo qual o sujeito se relaciona com a realidade e cria aquilo que para ele é "verdadeiro". Não é intuito de Zaratustra, portanto, destruir a referência ao mundo Weltbezug]

22 V. Gerhardt, 1988, p. 20.

112 | Cad. Nietzsche, Guarulhos/Porto Seguro, v.39, n.2, p. 97-122, maio/agosto, 2018. 
para restabelecer um universo de fabulação mítica, mas reavivar a consciência de que a única relação que o homem pode manter com o mundo é de caráter estético. Se outrora acreditava-se que com o nome se possuía também a essência da coisa - ou seja, confiava-se em uma teoria referencial do significado pela qual a linguagem era capaz de fornecer cópias exatas das coisas - por meio da retórica Nietzsche visa explicitar que a passagem da coisa ao nome se realiza mediante uma série de transposições artísticas entre [duas] esferas completamente heterogenias, sem oferecer qualquer garantia de correspondência. No famoso aforismo de Humano, demasiado humano, intitulado "A linguagem como suposta ciência", se lê:

$\mathrm{Na}$ medida em que por muito tempo acreditou nos conceitos e nomes das coisas como aeternae veritates [verdades eternas], o homem adquiriu esse orgulho com que se ergueu acima do animal: pensou ter realmente na linguagem o conhecimento do mundo. $\mathrm{O}$ criador da linguagem não foi modesto a ponto de crer que dava às coisas apenas denominações, ele imaginou, isto sim, exprimir com as palavras o supremo saber sobre as coisas; [...] Muito depois - somente agora - os homens começam a ver que, em sua crença na linguagem, propagaram um erro monstruoso (MA I/HH I, 11, KGW IV, II, p. 26$)^{23}$.

Sendo assim, aquilo que Nietzsche critica é a ideia de conhecimento que repousa sobre essa concepção de linguagem: de que ao homem é possível refletir fielmente a realidade sem a intervenção de uma elaboração criativa. A verdade não é mais pensada como adaequatio intellectus et rei, mas unicamente como reelaboração artística dos impulsos que provêm do mundo exterior. "Vontade de potência" é o nome que Nietzsche dá à atividade incessante de organização do fluxo informado pelas percepções em um mundo estável que é tomado como verdadeiro. A imagem metafísica de um mundo povoado por sujeitos que exercitam ações tendo finalidades como base e que são moralmente responsáveis por esses propósitos,

23 Trad. de Paulo César de Souza.

Cad. Nietzsche, Guarulhos/Porto Seguro, v.39, n.2, p. 97-122, maio/agosto, 2018. 
Zavatta, B.

nada mais é, portanto, que a transposição artística [künstlerische Übertragung] das exigências psíquico-físicas da uma determinada forma de vida. Uma forma de vida, segundo Nietzsche, que deve ser superada.

A "transvaloração de todos os valores", que Zaratustra assume, consiste precisamente na criação de uma nova visão de mundo, isenta de todo finalismo ou teleologia, e sobretudo de um novo tipo humano, capaz de afirmá-la com alegria. Paolo D’Iorio, em seu estudo sobre o eterno retorno, traz à luz como essa teoria de modo algum é nova: sem considerar os estoicos e Epicuro, que Nietzsche reconhece explicitamente como seus predecessores, a ideia de uma eterna repetição dos acontecimentos humanos, sem qualquer possibilidade de intervenção, é uma espécie de topos literário, fonte de desespero e angústia, que pode ser encontrado do Eclesiastes até Marco Aurélio, de Leopardi até autores certamente conhecidos por Nietzsche, como Schopenhauer e Hartmann. Estes últimos, com formulações surpreendentemente similares àquelas do famoso aforismo 341 da Gaia Ciência, imaginam ofertada ao homem a possibilidade de reviver mais uma vez, nas mesmas condições, os mesmos acontecimentos da sua vida, e concluem afirmando que ele provavelmente preferiria desaparecer no nada, caso essa eventualidade acontecesse $^{\mathbf{2 4}}$. A novidade nietzschiana, portanto, não consiste na doutrina do retorno propriamente dita, mas na possibilidade de criar uma nova humanidade que finalmente considere esse pensamento como "leve e beato" (KGW VII, I, p. 637; OFN VII, I, II, p. 266).

\section{Retórica como Welt und Lebensgestaltung}

Quem é, afinal, o Zaratustra de Nietzsche? Ele, como nos diz Heidegger, é o mestre do eterno retorno do igual. Sem dúvida, deve-se a Heidegger o mérito de ter sido o primeiro a reconhecer

24 P. D’Iorio, 1995, p. 192-193.

114 Cad. Nietzsche, Guarulhos/Porto Seguro, v.39, n.2, p. 97-122, maio/agosto, 2018. 
que o estilo, no Zaratustra, desenvolve uma função capital e não meramente acessória ou ornamental. Não seria nem útil, nem possível, considerar a doutrina do eterno retorno separadamente da figura do mestre que a ensina, bem como tentar identificar um "conteúdo" filosófico "subjacente" ao estilo com o qual é comunicado, visto que o que está em jogo, nessa obra, não é a adequação de uma teoria, mas a transformação da existência. O eterno retorno não é uma doutrina a ser aprendida, mas um pharmakon a ser tomado, que pode tanto envenenar o homem, conduzindo-o ao desespero e à destruição, quanto - se ele for suficientemente forte para tolerá-lo curá-lo da doença platônico-cristã, transformando-o. Sob essa ótica, diferentemente do filósofo tradicionalmente compreendido que, com expedientes retóricos, tenta conduzir à verdade aquele que não é filósofo, Zaratustra assemelha-se a um sofista, que visa transformar, por meio do discurso, a alma daquele que o escuta, permitindo que este crie a própria verdade. "A palavra é um grande dominadora", escreve Górgias no Encômio a Helena, "que, com um corpo muito pequeno e invisível, sabe compreender coisas divinas; com efeito, é capaz de acalmar o medo, e eliminar a dor, e suscitar a alegria, e aumentar a compaixão" ${ }^{\text {25 }}$.

Blumenberg, por sua vez, demonstra não ter compreendido inteiramente o sodalício nietzschiano entre arte e ciência - instaurado após a superação da separação entre mundo verdadeiro e mundo aparente -, quando sustenta que o "mito" nietzschiano do eterno retorno involuntariamente volta a assemelhar-se à "velha e refutada ideia de verdade", em virtude da fundamentação e exclusividade que pretende possuir. Segundo Blumenberg, paradoxalmente, justo no momento em que Nietzsche deseja reavivar o mito no lugar da verdade, esta última reaparece em cena:

25 H. Diels e W. Kranz 1969, 82 B 11(8). Cf. também B. Cassin, 2002, p. 57. 
Zavatta, B.

Em Nietzsche, a ideia inicial da beleza da mentira é refutada, por assim dizer, sozinha, na experiência que ele terá, menos de uma década após, em Silvaplana: que a mais bela das belas mentiras está em frente a ele, como uma das velhas verdades desprezadas. Ela se comporta como uma dessas verdades, na medida em que se aproxima da "seriedade" da demonstrabilidade, da "prestação" da responsabilização absoluta do homem $^{26}$.

De fato, no início dos anos oitenta, Nietzsche chega à conclusão de que o conhecimento que a "falsificação" artística do real, operada pelo homem por meio da linguagem, é inevitável, que não é possível se liberar da aparência e do erro sem perder, junto a isso, também a verdade e a realidade. Mas reconhecer a multiplicidade de condições que levaram a tais perspectivas sobre coisas que constituem a nossa história e a nossa ciência ainda não é suficiente: para que o perspectivismo seja assimilado como condição fundamental de todo nosso conhecer e agir, é necessário tornar-se criador:

Quem pensar que a remissão a essa origem e a esse invólucro nebuloso de ilusões for suficiente para aniquilar esse mundo tido como substancial, essa assim chamada "realidade", não passaria de um grande tolo! Apenas como criadores podemos aniquilar! Mas tampouco esqueçamos isso: basta criar novos nomes, e valorações, e verossimilhanças, para criar, aos poucos, novas "coisas" (KGW V, II, p. 98).

Zaratustra ensina que apenas o criar liberta efetivamente o homem do "espírito de gravidade", o qual lhe impõe valores e verdades como eternos e imodificáveis - como se fossem pedras pesadas para carregar - até esmagá-lo sob o peso da veneração. $\mathrm{O}$ "espírito de gravidade" anão disse: "Bom para todos, mau para todos" (KGW VI, I, p. 237 - Za/ZA, III, Do espírito de gravidade) ${ }^{27}$. Esses podem ser silenciados apenas por aqueles que têm a coragem de

26 H. Blumenberg, 1991, p. 304.

27 Trad. de Paulo César Souza.

116 | Cad. Nietzsche, Guarulhos/Porto Seguro, v.39, n.2, p. 97-122, maio/agosto, 2018. 
descobrir sua própria natureza e determinar sua própria lei, fazendo voar, assim, "todas as pedras fronteiriças", isto é, revolucionando as coordenadas do mundo que lhes é imposto como "verdadeiro" e "justo". Por isso Zaratustra adverte:

Por muitos caminhos e meios diferentes alcancei minha verdade; não apenas por uma escada subi às alturas de onde meu olho vagueia pelas distâncias que são minhas.

E somente com relutância perguntei pelos caminhos - isto sempre repugnou ao meu gosto! Preferi perguntar e tentear os próprios caminhos.

Um perguntar e tentear era todo o meu andar: - e, em verdade, deve-se aprender também a responder a tal perguntar! Mas este - é meu gosto:

- não que seja bom ou seja ruim, mas meu gosto, de que não me envergonho nem escondo.

"Este - é o meu caminho, - qual é o vosso?", assim respondi aos que me perguntaram pelo "caminho". Pois o caminho -não existe! (Za/ZA, III, Do espírito de gravidade, KGW VI, I, p. 237)

Zaratustra, portanto, convidando cada um à descoberta de si, da própria natureza em sua unicidade, exclui, por princípio, a ideia de uma normatividade universal, de um modelo ao qual se conformar. Mas como se chega a descobrir a própria natureza e a determinar a própria lei?

Em Tempo e Narrativa, Ricoeur, tendo como ponto de partida a análise da Poética, de Aristóteles, observa que a narração ou, mais especificamente, a construção da intriga, configura múltiplos e dispersos eventos, inserindo-os em uma perspectiva de sentido, deixando, assim, emergir uma realidade que antes não era acessível. "Compor a intriga já é fazer surgir o inteligível do acidental, o universal do singular, o necessário ou o verossímil do episódico"²8. A modalidade do "como se", caracterizadora do âmbito da ficção, abre, segundo Ricoeur, uma dimensão criativa, autopoiética, na qual o sujeito constrói a própria história e a própria identidade,

28 P. Ricoeur, 1994, p. 70. 
Zavatta, B.

reecontrando- $a$ no interior da própria vivência. Tal operação é, ao mesmo tempo, inventiva e reconstrutiva: a verdade de uma vida é reencontrada em seu curso experencial construindo uma ordem de sentido para ele ${ }^{\mathbf{2 9}}$. A verdade emerge, portanto, do discuso, ou melhor, da composição dos fatos em uma narração.

Aplicando essa hipótese interpretativa a Zaratustra, podemos sugerir que o pensamento do eterno retorno oferece precisamente uma "modelação" estética da existência, uma sua configuração possível. Viver "como se" tudo viesse a retornar eternamente independentemente das considerações sobre a plausabilidade científica dessa teoria - dá ao indivíduo a possibilidade de configurar os fatos de sua vida dentro de uma certa perspectiva, qual seja, aquela pela qual cada coisa deverá se repetir de maneira idêntica pela eternidade. Dizer "sim" a tudo que conduziu até o momento presente, faz com que a existência, por ser acidental e irresoluta, transcenda e adquira inteligibilidade, dotando-se de um significado que, embora sempre provisório, ainda assim é regulativo. A configuração dos eventos de nossa vida em uma figura unitária oferece a possibilidade de considerá-los não mais como acidentais, mas como necessários, como aneis de uma corrente de fatalidade incontornável. Daqui, poder-se-ia assumir a decorrência do sentimento do amor fati e o certeiro confiar em uma "providência pessoal" (KGW V, II, p. 199) que permeiam a Gaia Ciência. Dessa maneira, também o dissídio que sempre reaparece na filosofia de Nietzsche - encontraria uma conciliação entre fatalismo e auto-criação. Encontrar a própria natureza requer, de fato, um esforço criativo: para ser aquilo que desde sempre somos devemos vir a sê-lo.

29 No verbo latino invenio, que possui o duplo significado de "inventar" e "encontrar", a distância entre as duas modalidades de obter uma verdade é reduzida. Ricoeur toma como exemplo, para esse tipo de operação, o trabalho do historiador e do psicanalista, que re-constroem uma história, configurando eventos dispersos em uma "verdade" que antes não existia.

$30 \mathrm{O}$ aforisma demonstra como também os erros adquirem valor e necessidade quando incluídos dentro de uma ordem de sentido.

118 | Cad. Nietzsche, Guarulhos/Porto Seguro, v.39, n.2, p. 97-122, maio/agosto, 2018. 
No capítulo de Zaratustra intitulado Da árvore na montanha, Zaratustra encontra um jovem sob uma árvore e volta-se para ele assim como Cristo para Natanael embaixo da figueira - oferecendolhe uma interpretação sobre seu estado de ânimo. Este, surpreso, se pergunta como Zaratustra soube ler tão claramente dentro dele. E Zaratustra, sorrindo, responde enigmaticamente: "Algumas almas jamais descobrimos, a não ser que antes as inventemos [Manche Seele wird man nie entdecken, es sei denn, dass man sie zuerst erfindet]" (Za/ZA, I, Da árvore na montanha, KGW VI, I, p. 47) ${ }^{31}$. Eis, então, quem é o Zaratustra de Nietzsche: segundo suas próprias palavras, é um "poeta, decifrador de enigmas e redentor do acaso".

E este é todo o meu engenho e esforço, eu componho e transformo em um o que é pedaço, enigma e apavorante acaso [und das ist all mein Dichten und Trachten, dass ich in Eins dichte und zusammentrage, was Bruchstück ist und Räthsel und grauser Zufall] (Za/ZA, I, Da redenção, KGW VI, I, p. 173).

No capítulo intitulado Da visão e enigma, que representa o momento culminante do drama, encontramos Zaratustra e o anão frente a um portal chamado "Instante", ponto de convergência dos caminhos do passado e do futuro. É em frente a esse portal que os dois se encontram a refletir sobre o eterno retorno de todos as coisas, isto é, sobre o fato de que os dois caminhos, no fundo, são parte de um único círculo. $\mathrm{O}$ espírito de gravidade anão irrita Zaratustra porque repete mecanicamente essa doutrina sem aplicá-la à própria vivência, sem compreender como a verdade emerge apenas da "modelação" da própria existência. Segundo Zaratustra, o espírito de gravidade torna - paradoxalmente - "tudo tão leve" (Za/ZA, I, Da redenção, KGW VI, I, p. 196). "O peso mais pesado [das grösste Schwergewicht]" é, de fato, a pergunta: "Você quer isso uma vez e ainda inúmeras vezes?" (KGW V, II, p. 250), que conduz a configurar os fatos da própria vida dentro de uma nova perspectiva. Não por acaso, após

31 Trad. de Paulo César Souza. 
Zavatta, B.

ter liquidado como banal a resposta do anão, Zaratustra volta o pensamento para a própria infância, ao horror quase desmoronante do próprio passado, e é agora assaltado pela visão do pastor com a serpente na boca.

A serpente representa precisamente a ideia da eterna repetição do idêntico que, tradicionalmente, era utilizada para depreciar a existência terrena em sua vaidade e insensatez. Após a mordida com a qual arranca a cabeça da serpente, ou seja, após a aplicação das novas categorias interpretativas à própria vida, o pastor é "transformado [ein Verwandelter]" (KGW VI, I, 193), porque conquistou uma nova visão de si mesmo e da existência em sua complexidade. O horror ao próprio passado, na sua dolorosa acidentalidade e irreversibilidade, se transforma em alegria no momento no qual compreende que "sim, é assim e deve ser assim".

"Foi": assim se chama o ranger de dentes e solitária aflição da vontade. Impotente quanto ao que foi feito - ela é uma irritada espectadora de tudo que passou. [...] Todo "Foi" é um pedaço, um enigma, um apavorante acaso - até que a vontade criadora fala: "Mas assim eu quis!" - Até que a vontade criadora fala: "Mas assim eu quero! Assim quererei!" (KGW VI, I p. 177) ${ }^{32}$

Da configuração dos fatos da própria vida dentro de uma ordem de sentido, emerge, assim, uma nova verdade e, junto a ela, também o tipo humano em condições de afirmá-la. Um homem "transformado", finalmente capaz de celebrar a existência em sua complexidade, com aquilo que nela existe de doloroso e trágico, e de aceitar com alegria a realidade em sua característica efêmera, ambígua, contraditória. Zaratustra, como retórico e sofista, oferece os instrumentos de modo que cada um possa configurar, por meio do discurso, a própria verdade, curando as feridas deixadas na alma pelo acidental e transformando a própria visão de mundo.

32 Ibidem, p. 177 (p. 172).

$120 \mid$ Cad. Nietzsche, Guarulhos/Porto Seguro, v.39, n.2, p. 97-122, maio/agosto, 2018. 


\begin{abstract}
The article aims to explore the place of rhetoric in Nietzsche's thought. Taking as a starting point the position assumed by the philosopher at the time and his struggle against European's and modern's contempt for the rhetorical art, it intends to show the modes by which Nietzsche enhances rhetoric. Taking up the positive character Aristotle assigns to rhetoric as a dynamis, Nietzsche considers it as a biological and natural disposition, taking language itself as a result of rhetorical arts. He furthermore calls for the tradition of ancient sophists, with whom he shares the vision about the intimate connection between language and rhetorics, and that's why he distrusts the capacity of attaining the truth, the German philosopher creates the figure of Zarathustra to answer the appeal of an era of overcoming religious and metaphysical values thanks to the decline of will to truth. Also spoke Zarathustra must then be understood in the context of a renewed cepticism, in which the truth is not something already given, but rather something that the discourse each time creates and imposes, in an infinite succession of perspectives.
\end{abstract}

Keywords: Zarathustra, rhetoric, language, sophist.

\title{
Refererências bibliográficas
}

BLUMENBERG, H. Approccio antropologico all'attualità della retorica. In: La realtà in cui viviamo, trad. it. di M. Milano: Cometa, Feltrinelli, 1987.

. Elaborazione del mito. trad. it. di B. Argenton. Bologna: Il Mulino, 1991.

BURCKHARDT, J. L'età di Costantino il Grande, trad. it. di E. Dupré Theseider. Firenze: Sansoni, 1990.

CASSIN, B. L'effetto sofistico. Per un'altra storia della filosofia, Milano, Jaca Book 2002.

CURTIUS, E.R. Letteratura europea e medioevo latino, a c. di R. Antonelli, trad. it. di A. Luzzatto, M. Candela e C. Bologna. Firenze: La Nuova Italia, 1992.

DIELS, H. \& KRANZ, W. [a c. di]. I Presocratici. Testimonianze e frammenti. 2 vol., trad. it. di G. Giannantoni et al. Roma-Bari: Laterza, vol. II, 80 B 1, 1969.

D’IORIO, P. La linea e il circolo. Genova: Pantograf, 1995. 
Zavatta, B.

GERHARDT, V. Nietzsches ästhetische Revolution. In Pathos und Distanz. Studien zur Philosophie Friedrich Nietzsches. Stuttgart: Reclam, 1988.

GOTH, J. Nietzsche und die Rhetorik. Tübingen: Max Niemeyer, 1970.

HEGEL, G.W.F. Hegel. Lezioni di storia della filosofia, 4 voll., a c. di E. Codignola e G. Sanna. Firenze: La Nuova Italia, 1930, vol. I, t. 2.

KANT, I. Critica della facoltà di giudizio, a c. di E. Garroni e H. Hohenegger. Milano: Einaudi, 1999.

KOPPERSCHMIDT, J. Nietzsches Entdeckung der Rhetorik, In: KOPPERSCHMIDT, J. e SCHANZE, H (a c. di). Nietzsche, oder "Die Sprache ist Rhetorik. Munique: Wilhelm Fink Verlag, 1994, pp. 39-62.

NIETZSCHE, F. Sämtliche Werke. Kritische Studienausgabe (KSA). G. Colli. e M. Montinari. Berlin: Walter de Gruyter, 1980.

. Sämtliche Werke. Kritische Gesamtausgabe (KGW). Berlin/New York: Walter de Gruyter, 1967 - 1978.

. Humano, demasiado humano. Trad. de Paulo César de Souza. São Paulo: Cia. das Letras, 2000.

. Assim falou Zaratustra. Trad. de Paulo César de Souza. São Paulo: Cia. das Letras, 2009.

RICOEUR, P. Tempo e narrativa, tomo 1 , trad. português. de Constança Marcondes César. Campinas, SP: Papirus, 1994.

VICKERS. B. "Nietzsche im Zerrspiegel de Mans: Rhetorik gegen die Rhetorik". In: KOPPERSCHMIDT, J. e SCHANZE, H. (a c. di). Nietzsche, oder "Die Sprache ist Rhetorik. Munique: Wilhelm Fink Verlag, 1994, pp. 219-240.

ZAVATTA, B. "The Figurative Patterns of Reason: Nietzsche on Tropes as Embodied Schemata". In: DRIES, M. (ed.), Nietzsche on Consciousness and the Embodied Mind, Berlin: De Gruyter, 2013.

Artigo recebido para publicação em 23/02/2018 Artigo aceito para publicação em 17/06/2018

122 | Cad. Nietzsche, Guarulhos/Porto Seguro, v.39, n.2, p. 97-122, maio/agosto, 2018. 